\title{
Telemedicine and Human Resources for Health Crisis Management in the North West Region of Cameroon
}

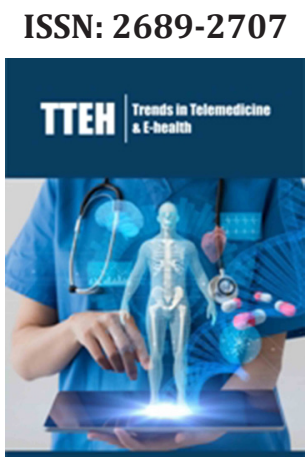

*Corresponding author: Promise Aseh Munteh, Department of Health Economics, Policy and Management, Catholic University of Cameroon (CATUC), Bamenda, Cameroon

\section{Submission: 海July 16, 2019}

Published: 䟧August 22, 2019

Volume 1 - Issue 5

How to cite this article: Promise Aseh Munteh, Wilfred Mbacham, Walter Swoboda. Telemedicine and Human Resources for Health Crisis Management in the North West Region of Cameroon. 1(5). TTEH. 000523. 2019. DOI: 10.31031/TTEH.2019.01.000523

Copyright@ Promise Aseh Munteh, This article is distributed under the terms of the Creative Commons Attribution 4.0 International License, which permits unrestricted use and redistribution provided that the original author and source are credited.

\author{
Promise Aseh Munteh ${ }^{1 *}$, Wilfred Mbacham ${ }^{2}$ and Walter Swoboda ${ }^{3}$ \\ ${ }^{1}$ Department of Health Economics, Policy and Management, Catholic University of Cameroon \\ (CATUC), Cameroon
}

${ }^{2}$ Professor of Public Health Biotechnology, Cameroon

${ }^{3}$ Professor of Health Management Information Systems, Germany

\begin{abstract}
Background: Shortages in personnel have been observed repeatedly in hospital settings thus resulting in Undue delay in rendering service, Neglect in patient care, Rough behavior of lower category of staff and poor information and guidance system. The aim was to assess the distribution of human resources for health per cadre and to provide evidence for the possibility of uptake of telemedicine in the Region as one of the solutions to bridge the gap on the shortage and uneven distribution of health workers.

Method: This was a Hospital-based cross-sectional study. The instrument used for data collection were structured questionnaires of 33 items. The four main hospitals in the Region were identified and included in the study and the rest of the health facilities were selected randomly.

Result: The study has shown a situation analysis of the health workforce in the Region indicating a total of 2,576 health workers out of which 127 are doctors with 55 general practitioners inclusive, 902 nurses/ midwifes and 1,547 constitute other categories of health workers such as, technicians, administrative and support staff. The results also revealed that Telemedicine is not a new idea to many of the health administrators in the Region and thus could be expanded to save lives. Also, the issues of privacy and confidentiality which is one of the principal drawbacks to the rapid advancement of telemedicine in most developed countries was not highlighted as a challenge by the respondents in this study giving telemedicine a good place in the Region. However, the main challenges were infrastructural related with lack of internet services and regular power cuts predominant and in this researchers' opinion, these drawbacks could easily be managed, thus, giving telemedicine a great chance in this fight. The region with a population of 1,876,356 persons only has 2 orthopedic surgeons and 4 pediatrician specialists.
\end{abstract}

Conclusion: Telemedicine is not new to most health care providers in the health facilities in the NWR of Cameroon and should be expanded to save lives.

Keywords: Telemedicine; Health; Human resources for health; Crises; E-health; Gap; Bridge

Abbreviation: NWR: North West Region; HRH: Human Resources for Health; ICTs: Information and Communication Technologies

\section{Introduction}

Timely access to health care in both urban and rural settings is a worldwide challenge. No nation that is committed to the health of her population can afford to replicate, in every community, all the resources required for comprehensive health care. On the other hand, as the potential for a universal internet access approaches reality, consumer access to health information and portals for health monitoring and health care-related services is assuming increasing importance with telemedicine inclusive. Telemedicine is the ability to provide interactive health care utilizing modern technology and telecommunication. It can be defined also as the use of electronic information and communications technologies to provide and support health care when distance separates the participants [1].

Telemedicine encompasses all of the health care, education, information and administrative services which can be transmitted over distances by telecommunications technologies [2]. Telemedicine covers a range of technologies, including telephone, radio, facsimile, modem, and video. It may be conducted in real time, as with interactive video, or asynchronously, for the transmission of text or graphic data, auditory verbal information, still images, short video 
clips, and full-motion video. Robotics and virtual reality interfaces have been introduced into some experimental applications [3]. What is being reported in this article is the actual situation of health workers in the NWR per cadre, the knowledge of various heads of the health facilities on telemedicine and their subscription to this information and communication technology as an option to bridge the gap on the shortage and uneven distribution of HRH especially in the rural areas.

\section{Methods}

This was a Hospital-based cross-sectional study.

\section{Result}

The response was received from 78 questionnaires out of a total of 80 sent out. A total of 76 were suitable for analysis giving a response rate of $95 \%$. From these responses a total of 127 doctors and 2,449 of other categories of health workers giving a grand total of 2,576 were registered workers within the 76 health facilities. A situation analysis of these workers per cadre and per hospital demonstrates that there are 127 doctors, 55 of whom are general practitioners (GPs), 22 interns and 50 are specialists, while the other categories of staff had 2,449 persons of which the largest were nursing assistants (470) (Table 1).

Table 1: A situation analysis of health workers in the NWR per Cadre.

\begin{tabular}{|c|c|}
\hline \multicolumn{2}{|l|}{ (1) Doctors } \\
\hline Specialty & Number \\
\hline General Practitioners & 55 \\
\hline Pediatricians & 4 \\
\hline Orthopedics & 2 \\
\hline Ophthalmologists & 3 \\
\hline General Surgeons & 6 \\
\hline Internists & 7 \\
\hline OBGyns & 5 \\
\hline Urologists & 3 \\
\hline Dentist & 5 \\
\hline Pharmacists & 9 \\
\hline Dermatologists & 1 \\
\hline Cardiologists & 3 \\
\hline ENT Surgeons & 2 \\
\hline Interns & 22 \\
\hline Sub-Total 1 & 127 \\
\hline \multicolumn{2}{|c|}{ (2) Other Categories of Health Workers } \\
\hline Nurses with a bachelor's degree (minimum) & 72 \\
\hline State Registered Nurses (A Levels + 3years) & 268 \\
\hline Midwives & 92 \\
\hline Nursing Assistants & 470 \\
\hline
\end{tabular}

\begin{tabular}{|c|c|}
\hline Pharmacy Staff & 145 \\
\hline Eye Care Staff & 19 \\
\hline Laboratory Staff & 218 \\
\hline X-Ray Staff & 23 \\
\hline Ultrasound Staff & 19 \\
\hline Dentistry Staff & 26 \\
\hline Physiotherapy Staff & 24 \\
\hline Auxiliary Staff & 240 \\
\hline Administrative Staff & 82 \\
\hline Chaplaincy/Social Workers & 62 \\
\hline Housekeeping Staff & 213 \\
\hline Maintenance Staff & 112 \\
\hline Mortuary Attendants & 25 \\
\hline Other Staff & 339 \\
\hline Sub-total 2 & 2,449 \\
\hline Grand Total 1+2 & 2,576 \\
\hline
\end{tabular}

\section{Electricity Supply and Provision for Stability}

Out of the 76 health facilities that participated in the study, 71 of them had electricity giving a percentage score of $93.4 \%$ as indicated in Table 2 below. Also, 38 (50\%) of the health facilities had both hydroelectricity and a stand-by generator while the other 38 (50\%) either had electricity or not, without a stand-by generator as presented in Figure 1 below, yes represent health facilities with a stand-by generator while no represent health facilities without a stand-by generator. Of the 54 heads of the health facilities with computer knowledge, 43 (79.6\%) of them owned their personal computers and 11(20.4\%) did not have personal computers. Availability, knowledge and ownership of at least a computer were also linked to usage by the different respondents (Figure 2).

Table 2: Health Facilities with Electricity Supply.

\begin{tabular}{|c|c|c|}
\hline Respondents & Frequency & Percent \\
\hline YES & 71 & 93.4 \\
\hline NO & 5 & 6.6 \\
\hline Total & 76 & 100.0 \\
\hline
\end{tabular}

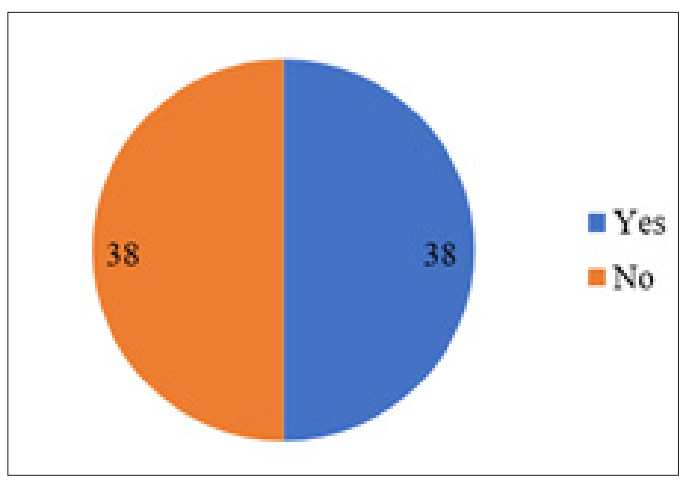

Figure 1: Health facilities with stand-by generator. 


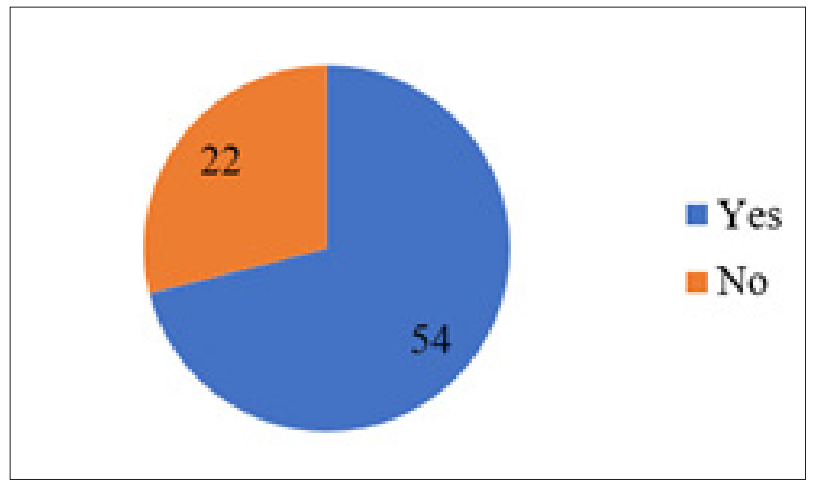

Figure 2: Heads of health facilities with Computer Knowledge.

Availability of Telephone/Internet Signals and the Strength

The different health facilities were tested on the availability of telephone and internet connectivity and also how good the signals were. Out of the 76 health facilities, $70(92.1 \%)$ had at least 1 mobile telephone signal while only 6(7.9\%) did not have (Figure 2 ).

\section{Knowledge of Telemedicine}

The knowledge of the various representatives of the health facilities was tested on telemedicine generally using 5 questions. The results are presented below. Telemedicine was defined as the use of electronic information and communication technologies to provide and support health care when distance separated the participants. Of the respondents, 23 said they strongly agreed, 43 agreed, 2 disagreed and 8 had no idea. A total of $66(86.8 \%)$ of the respondents agreed at least to the suggested definition of telemedicine indicating a reasonably good knowledge on this topic while $10(13.2 \%)$ either disagreed or had no idea (Figure 3).

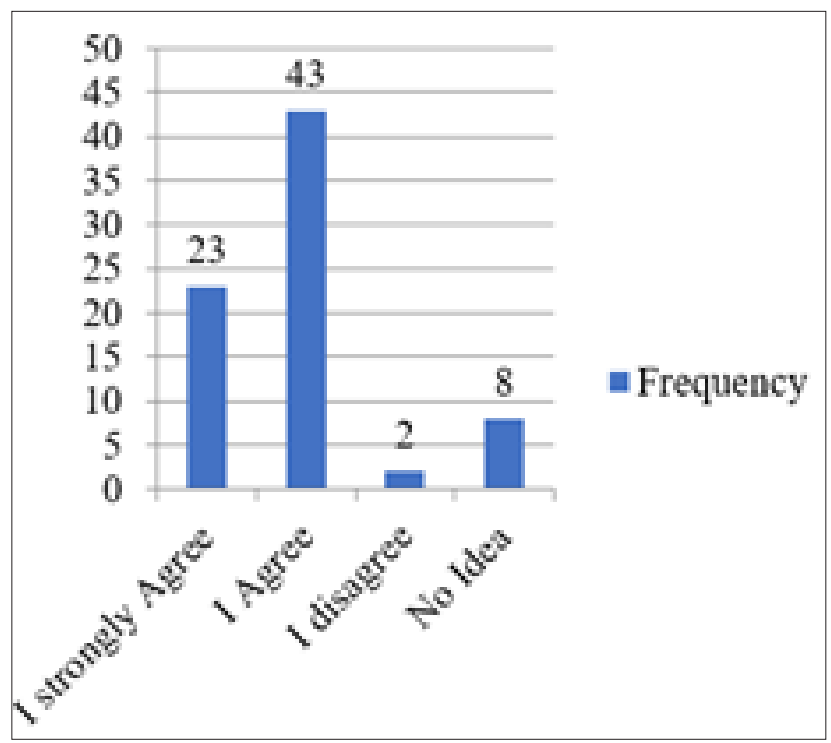

Figure 3: The use of ICTs to Provide and Support Health Care at a Distance.
Perceptions of Heads of Health Facilities on the Human Resources for Health Crises in the NWR

The viewpoint of the different heads of the health facilities on the situation of HRH was investigated in the Region. We were interested to know if there was a crisis. In the response that followed, 49 of such heads quantified the crises situation of the HRH in the Region to be acute, 21 said the crises was little, one said there was no crises and 5 did not know whether or not any crises exist. Figure 4 above reveals that 49 of the respondents quantified the crises situation of the HRH in the Region to be acute, 21 said the crises was little, 1 said there was no crises and 5 did not know whether or not any crises exist. Some 64 (84.2\%) health facilities had high interest, $10(13.2 \%)$ had low interest on the linkage and $2(2.6 \%)$ had no interest in linking theirs to any other facility via telemedicine (Figure 5).

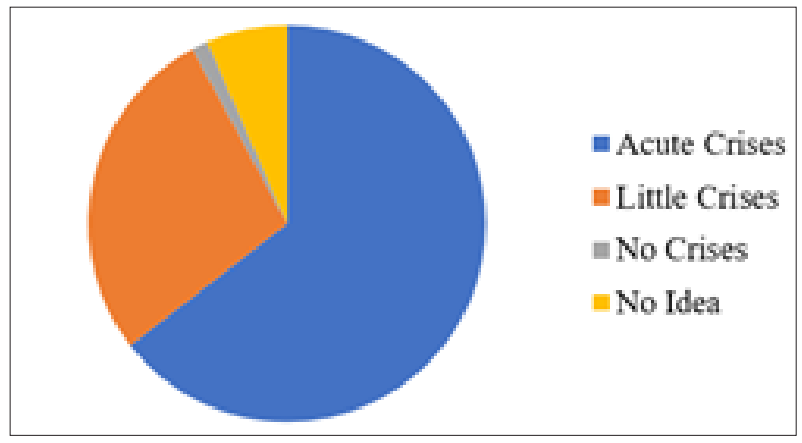

Figure 4: Viewpoint of heads of health facilities on the HRH Crises in the NWR.

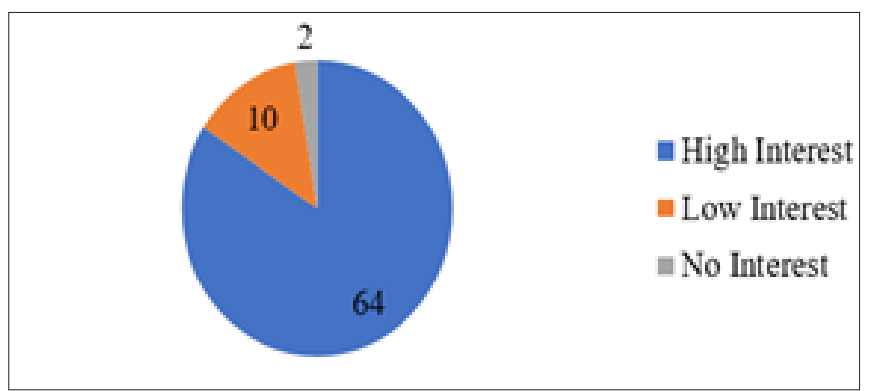

Figure 5: Interest on Telemedicine Linkage.

\section{Advantages of using Telemedicine}

In an open-ended question, we wanted the respondents to suggest some advantages of using telemedicine to provide health care in their various facilities. The responses were grouped and presented in Table 3 below.

\section{Disadvantages of using Telemedicine}

To understand what respondents perceived as disadvantages of using telemedicine the responses were as varied but reliable power supply and lack of internet services stemmed out to be the most serious problems (Table 4). 
Table 3: Some advantages of using Telemedicine.

\begin{tabular}{|c|c|c|}
\hline Question & Response & Total with same response \\
\hline \multirow{9}{*}{ Advantages of using Telemedicine } & Seek specialist care & 23 \\
\hline & Rapid interventions & 15 \\
\hline & Interactive care & 9 \\
\hline & Solve personnel crises & 2 \\
\hline & Good Archiving & 1 \\
\hline & Reduce the cost of referral & 23 \\
\hline & No Idea & 4 \\
\hline & Learning experience & 1 \\
\hline & Improve consultation & 2 \\
\hline
\end{tabular}

Table 4: Some disadvantages of using telemedicine.

\begin{tabular}{|c|c|c|}
\hline Question & Response & Total with Same Response \\
\hline \multirow{12}{*}{ Disadvantages of Using Telemedicine } & Regular power failures (cuts) & 17 \\
\hline & Low level of ICT among staff & 8 \\
\hline & Lack of Finances to set up telemedicine & 9 \\
\hline & Lack of confidentiality & 4 \\
\hline & Lack of interaction between patient and the Doctor & 4 \\
\hline & Misrepresentation of patients' condition & 4 \\
\hline & Lack of physical examination & 5 \\
\hline & Over dependence on specialists & 1 \\
\hline & No Idea & 6 \\
\hline & Lack of reliable internet services & 19 \\
\hline & Delay to get the Doctor online & 1 \\
\hline & Lack of equipment & 2 \\
\hline
\end{tabular}

Acceptance to Act on Medical Advice via Telemedicine

To know if the different health facilities could accept and act on advice given via telemedicine by a senior colleague in another health facility, slightly above half of the respondents would accept (53.9\%) 43,4 with reservations and 2 had no idea.

Table 5: The use of telemedicine services to assist in bridging the gap on HRH shortage.

\begin{tabular}{|c|c|c|}
\hline Question & Response & Frequency \\
\hline \multirow{2}{*}{$\begin{array}{l}\text { Feeling confident to use Telemedicine services bridge the gap on } \\
\text { HRH shortage. }\end{array}$} & Yes & 44 \\
\hline & No & 12 \\
\hline Total & & 56 \\
\hline \multirow{5}{*}{ Reasons for a yes response } & Exposure to specialized care & 23 \\
\hline & Improve personnel knowledge & 12 \\
\hline & Less expensive & 3 \\
\hline & Solve personnel crises & 3 \\
\hline & Reduce the cost of referral & 6 \\
\hline Total & & 47 \\
\hline \multirow{2}{*}{ Reasons for a no response } & No interaction & 2 \\
\hline & Lack of physical examination & 1 \\
\hline Total & & 3 \\
\hline
\end{tabular}


Telemedicine as an Option to Bridge the Gap on the Shortage of HRH

To ascertain the confidence of the various health facilities on looking at telemedicine services to be of assistance to them to help bridge the gap on the shortage and uneven distribution of HRH especially contacting specialists, a total of 56 participants responded to the question either by saying yes or no to the idea of using telemedicine services to assist bridge the gap on the shortage of HRH, especially contacting specialists. On giving their various reasons for either of these views, 47 participants gave positive reasons to the yes response instead of 44 implying that 3 respondents who did not provide an answer to the first part of the question went ahead to advance a reason and only 3 of the 12 respondents who said no to this idea went ahead to advance at least a reason. Exposure to specialized care, improvement on personnel knowledge and a reduction in the cost of referrals were ranked top on the reasons for saying yes and the lack of personal interaction between the patient and the specialist was top for the no response by the participants (Table 5).

\section{Discussion}

The situation analysis of the health workers in the NWR as presented in Table 6\&7 indicated that the 76 health facilities had a total of 127 doctors with 55 being general practitioners, 9 pharmacists, 7 internists, 6 general surgeons, 5(dentists, OBGyns), 4 pediatricians, 3(ophthalmologists, Urologists and Cardiologists), 2(ENT Surgeons, Orthopedics), 1 dermatologist and 22 others. The large number for others came from a single health facility and these were interns who are undergoing specialization in internal medicine and general surgery. It is worth noting that 85 representing approximately $70 \%$ of these doctors are from only 6 of the 76 health facilities, all around the capital city Bamenda and $110 \mathrm{kms}$ furthest. Interestingly, of the 85 doctors from these six health facilities, only $20(23.5 \%)$ are from a public hospital while $65(76.5 \%)$ are from the Faith-Based and private for-profit health facilities.

Table 6: List of countries with critical deficit of health workforce.

\begin{tabular}{|c|c|c|c|c|c|c|}
\hline \multicolumn{3}{|c|}{ African Region } & Region of the & Eastern Mediterranean & South-East Asia & Western Pacific \\
\hline Angola & Eritrea & Mauritania & El Salvador & Afghanistan & Bangladesh & Cambodia \\
\hline Benin & Ethiopia & Mozambique & Haiti & Djibouti & Bhutan & Lao Peoples D R. \\
\hline Burkina Faso & The Gambia & Niger & Honduras & Iraq & India & Papua New Guinea \\
\hline Burundi & Ghana & Nigeria & Nicaragua & Morocco & Indonesia & \\
\hline Cameroon & Guinea & Rwanda & Peru & Pakistan & Myanmar & \\
\hline CAR & Guinea-Bissau & Senegal & & Somalia & Nepal & \\
\hline Chad & Kenya & Sierra Leone & & Yemen & & \\
\hline Comoros & Lesotho & Togo & & & & \\
\hline Congo & Liberia & Uganda & & & & \\
\hline Cote d'Ivoire & Madagascar & $\begin{array}{c}\text { United Republic of } \\
\text { Tanzania }\end{array}$ & & & & \\
\hline DRC & Malawi & Zambia & & & & \\
\hline Equatorial Guinea & Mali & Zimbabwe & & & & \\
\hline
\end{tabular}

Table 7: List of some telemedicine projects in the State of Bavarian, Germany.

\begin{tabular}{|c|c|c|}
\hline No & Project & Project management / carrier \\
\hline 1 & A home telehealth service for patients with severe COPD & Linde Healthcare \\
\hline 2 & $\begin{array}{l}\text { Electronic ECG transmission in acute ST elevation } \\
\text { myocardial infarction }\end{array}$ & \\
\hline 3 & SUCCESS-C-Studie & \\
\hline 4 & By-Ophtel-Telematics in Ophthalmology (Ophthalmology) & \\
\hline 5 & By-Telepresence-Telematics in Pathology & \\
\hline 6 & ByMedCard-chip cards in the Bavarian health network & GSF-Institute of Medical Informatics \\
\hline 7 & Bavarian Health Card and Communication (BGK) & $\begin{array}{l}\text { GSF-Institute of Medical Informatics (since } 1 \text { January } 2008 \text { "Helmholtz } \\
\text { Zentrum München-German Research Center for Health and Environment") }\end{array}$ \\
\hline 8 & $\begin{array}{l}\text { ByMedCard (chip cards in the bavarian health network) } \\
\text { Bavaria-Hungary }\end{array}$ & GSF? \\
\hline 9 & $\begin{array}{l}\text { Health Care Professionals Protocol (HCCP)-the standard } \\
\text { for secure, proprietary and demonstrable transmission of } \\
\text { medical data }\end{array}$ & KVB \\
\hline
\end{tabular}




\begin{tabular}{|c|c|c|}
\hline 10 & $\begin{array}{l}\text { EMPOWER-An innovative software system based on } \\
\text { intelligent, knowledge-based treatment pathways for the } \\
\text { independent therapy of diabetes patients }\end{array}$ & $\begin{array}{l}\text { Salzburg Research Forschungsgesellschaft mbH, Austria beteiligt sind u.a.: } \\
\text { Ministry of Health (MoH), Turkey; Intracom Telecom, Greece; Software } \\
\text { Research and Development and Consultancy Ltd., Turkey; Università della } \\
\text { Svizzera italiana - Institute of Communication and Health, Switzerland; GO } \\
\text { IN Integrationsmanagement-und Beteiligungs-GmbH, Germany; Helmholtz } \\
\text { Zentrum München-Institute for Biological and Medical Imaging, AG: } \\
\text { Medical Information Systems, Germany }\end{array}$ \\
\hline 11 & Join In-An interactive social portal for the elderly & $\begin{array}{l}\text { Institute for Biological and Medical Imaging, Medical Information Systems, } \\
\text { Helmholtz Zentrum München- German Research Center for Environment } \\
\text { and Health, Neuherberg; Diakonie Munich-Moosach, Munich Pasife GmbH, } \\
\text { Lichtenfels }\end{array}$ \\
\hline 12 & Health Online Service (HOS)-Health Information Service & Health Online Service (HOS) GmbH \\
\hline 13 & ByMedCard-Health-Care-Professionals-Protocol (HCCP) & Medis, Helmholtz Zentrum München, Neuherberg \\
\hline 14 & ENDOTEL & Klinikum rechts der Isar of the Technical University of Munich \\
\hline 15 & New communication technologies in emergency medicine & Dienstleistungs GmbH Stamsried (now Cham) \\
\hline 16 & TeleDiab-telemedicine unit in the diabetes center & \\
\hline 17 & TESS & $\begin{array}{l}\text { Six hospitals in the region of Central Swabia (Kreis Lindau Hospital, } \\
\text { Nördlingen Foundation Hospital, Memmingen Hospital, Oettingen District } \\
\text { Hospital, Kempten Hospital, Danube Ries Clinic Donauwörth) - Günzburg } \\
\text { District Hospital (Professor Dr. Dr. Widder, Senior Physician Dr. Wiborg) } \\
\text { has received this innovative project the BayernOnline-Preis 2004. With } \\
\text { "TESS II" the project "TESS I" is continued and modified according to the } \\
\text { findings from TESS I. The costs for the acute stroke care "TESS II" have } \\
\text { taken over the health insurance companies }\end{array}$ \\
\hline 18 & NEVAS & \\
\hline 19 & Ultrastrukturelle Telepathologie & University Hospital Regensburg has in cooperation with companies (??) \\
\hline 20 & $\begin{array}{l}\text { Networking of practice and clinic for needs-based and } \\
\text { economical patient care }\end{array}$ & NetCom GmbH \\
\hline 21 & History software & District hospital Simbach a. Inn \\
\hline 22 & $\begin{array}{l}\text { Telemedicine communication center with affiliated } \\
\text { technology and further education center }\end{array}$ & Telehaus Dienstleistungs GmbH, Regensburg Hospital \\
\hline 23 & HERA-Heart attack network Augsburg & Klinikum Augsburg (I. Medical Clinic), Herzzentrum Augsburg-Schwaben \\
\hline 24 & Telemedicine cardiac surgery network & Hospital Augsburg \\
\hline 25 & Health across Borders & \\
\hline 26 & Digital Signature/Cryptography & Clinic Landsberg am Lech \\
\hline 27 & Global digital Tumordokumentationssystem & Tumor Center Regensburg \\
\hline 28 & $\begin{array}{l}\text { Development of a process-controlled system for the format- } \\
\text { independent semiautomatic conversion of existing telematic } \\
\text { data from any primary and host systems by means of an } \\
\text { engine into any secondary and subsystems }\end{array}$ & \\
\hline 29 & $\begin{array}{l}\text { Living with cystic fibrosis- telemedicine-based monitoring } \\
\text { of patients with cystic fibrosis }\end{array}$ & $\begin{array}{l}\text { Department of Internal Medicine Ludwig-Maximilians-University Munich } \\
\text { (LMU)+Cystic Fibrosis Ambulances of Dr. med. from Haunerschen } \\
\text { Children's Hospital Munich+University of Würzburg }\end{array}$ \\
\hline 30 & Medical data conversion system & \\
\hline 31 & Positron emission tomography (PET)- Mainfranken network & $\begin{array}{l}\text { between the Clinic and Polyclinic for Nuclear Medicine of the University of } \\
\text { Würzburg and two nuclear medical practices in Würzburg }\end{array}$ \\
\hline 32 & Rosenheimer care network via Internet (RoBIn) & City of Rosenheim \\
\hline 33 & $\begin{array}{l}\text { STENO-Stroke supply with telemedicine in northern Bavaria } \\
\text { (STENO pilot project, STENO network, STENO-QM) }\end{array}$ & $\begin{array}{l}\text { University of Erlangen and the Klinikum Nürnberg-Süd with the Klinikum } \\
\text { Forchheim and Kreisklinik Roth }\end{array}$ \\
\hline 34 & TelEp-Telemedical Network for Epilepsy in Bavaria & \\
\hline 35 & $\begin{array}{l}\text { Telemammography with computer assisted } \\
\text { Mammadiagnostik }\end{array}$ & $\begin{array}{l}\text { gynecological and radiological joint practice and the district hospital } \\
\text { Alzenau-Wasserlos has the project sponsor, the Aschaffenburg Hospital }\end{array}$ \\
\hline 36 & $\begin{array}{c}\text { Telemedicine in Neurology and Neurological Rehabilitation- } \\
\text { Speech Therapy }\end{array}$ & Neurology of the district hospital Bayreuth \\
\hline 37 & Telemedicine platform in pulmonology & $\begin{array}{c}\text { Hospital Donaustauf with specialist medical practices in the outpatient } \\
\text { area }\end{array}$ \\
\hline
\end{tabular}




\begin{tabular}{|c|c|c|}
\hline 38 & $\begin{array}{c}\text { Telemedical connection of the Department of Pediatric } \\
\text { Cardiology and Congenital Heart Defects in the German } \\
\text { Heart Center in Munich to referring physicians and aftercare } \\
\text { providers }\end{array}$ & $\begin{array}{c}\text { Department of Pediatric Cardiology and Congenital Heart Defects in the } \\
\text { German Heart Center Munich (DHM) }\end{array}$ \\
\hline 39 & $\begin{array}{c}\text { Telepsychiatric Consultation in Central Franconian } \\
\text { Hospitals-PSYCHKOM }\end{array}$ & $\begin{array}{l}\text { The psychiatric center, Clinic for Psychiatry and Psychotherapy at the Clinic } \\
\text { at the European Canal in Erlangen, two local hospitals-Klinikum Fürth and } \\
\text { Waldkrankenhaus St. Marien Erlangen-as well as the neurological center of } \\
\text { the Friedrich Alexander University Nuremberg-Erlangen }\end{array}$ \\
\hline 40 & Teletherapy - Subsystem Neurolinguistic Module & Technical cooperation partner (?), Specialist Clinic Herzogenaurach \\
\hline 41 & $\begin{array}{l}\text { TEMPiS - Telemedical pilot project for integrated stroke care } \\
\text { in the region South-East Bavaria }\end{array}$ & $\begin{array}{l}\text { Städtische Krankenhaus München-Harlaching (project sponsor) and the } \\
\text { Neurological Clinic of the University of Regensburg }\end{array}$ \\
\hline 42 & $\begin{array}{l}\text { Establishment and operation of a center for telemedicine in } \\
\text { the district of Bad Kissingen. }\end{array}$ & \\
\hline 43 & $\begin{array}{l}\text { Use of telemedical procedures to establish and further } \\
\text { develop innovative, location-independent care approaches } \\
\text { for home ventilation patients }\end{array}$ & \\
\hline 44 & $\begin{array}{c}\text { Development of an integrated telemedical care program for } \\
\text { dialysis patients }\end{array}$ & \\
\hline 45 & $\begin{array}{l}\text { Project electronic case file (eFA) - Munich-Coordinated } \\
\text { treatment through standardized communication }\end{array}$ & \\
\hline 46 & $\begin{array}{l}\text { SynX-Automated internet-based coaching program for } \\
\text { overweight and obese adolescents }\end{array}$ & \\
\hline 47 & $\begin{array}{l}\text { Telediagnosis of dysarthric disturbances by means of } \\
\text { acoustic speech signal analyzes (MAP-Online) }\end{array}$ & $\begin{array}{l}\text { EKN-Developmental Group Clinical Neuropsychology, Department of } \\
\text { Neuropsychology, Klinikum Bogenhausen, Städt. Klinikum München GmbH }\end{array}$ \\
\hline
\end{tabular}

This may be the reason why most of the private health facilities in the Region are observed to be always overcrowded with patients than the public health institutions. One of the health facilities that declined participation in this study is also a private and a referral hospital with not less than 10 doctors who are not included in the 85 above. Statistics from the Regional Delegation of Health for the NWR indicated a total of 100 doctors a little lower than the number obtained from the field with only 76 health facilities represented. This could partly be due to the 22 interns included in this study and also that some new doctors might have been recruited or posted to some of the health facilities within the year and the records are not yet up dated or just that the statistics submitted to the Regional Delegate's Office were incorrect. The worst scenario is that of only 1 dermatologist in the entire Region with 2.3 million inhabitants as per the 2010 population sensors to take care of also considering that skin diseases are common. Considering that they were only 127 doctors in the Region, it will imply 1 doctor to approximately 18,600 inhabitants.

The other category of health care workers showed that of the 2,449 available, 72 of them had a minimum of a bachelor of nursing degree, 268 were State Registered Nurses, 92 midwives, 479 nursing assistants, 145 pharmacy staff, 10 eye care staff, 218 laboratory staff of different levels, 23 X-Ray staff, 19 Ultrasound staff, 26 dentistry staff, 24 physiotherapy staff, 240 auxiliary staff, 82 administrative staff, 62 social workers/chaplains, 213 housekeeping staff, 112 maintenance workers, 25 mortuary attendants and 339 others. We tried to group these workers in to four categories with 902 who are supposed to be responsible for direct patient care giving an approximate ratio of $36.8 \%, 714$ provide support in areas of diagnostics, dental care, eye care and auxiliary services (making of beds, assisting to chat, taking vital signs and so on) giving a ratio of approximately 29.2\%, 494 provide counseling support, administrative and cleaning giving approximately $20.2 \%$ and 339 falls under others giving an approximate ratio of $13.8 \%$.

Of these 339 other workers, 160 of them are from just one institution giving a ratio $47.2 \%$. These include carpenters, masonries, electricians, herdsmen, gardeners, drivers/mechanics, security guards and teachers. Comparing with statistics from the Regional Delegation of Health, we realized that this did not quite tie with a huge difference. This could be because of wrong information or poor documentation either from the facilities or at the level of the Regional Office. No other article to compare these results with could be found indicating that this was the first study in this direction.

The assessment of the potential of ICTs availability and stability of electricity supply in the various health facilities as presented in Table 2; Figure $1 \& 2$ reveals very interesting results. In Table 2, 71 of the 76 health facilities under study had electricity supply and out of this number, 38 of them had provision for a back-up with a functional generator. This shows that the rural electrification process initiated in the country earlier is covering many rural areas. It also reveals that $38(50 \%)$ health facilities would have sufficient power to support the installation of telemedicine infrastructures. Interestingly, all the main hospitals in this study had both electricity and a stand-by generator and of the 38 health facilities with both, only 14 of them are in the main city. This shows that a reasonably good link could be established between the urban centers and those in rural areas via telemedicine because the facilities with 2 power supply options, all may not fail at the same time. We could not compare this with any study because noon has been conducted in this direction (Figure 4).

With regards to ICTs, $38(50 \%)$ of the health facilities had at least a computer while the other $38(50 \%)$ did not. Of the 38 health facilities with at least a computer, $26(68.4 \%)$ are private 
health facilities while 12 (31.6\%) are public facilities. All the health facilities (38) with computer(s) equally had electricity supply. Out of the 76 health facilities, $70(92.1 \%)$ had at least 1 mobile telephone signal while only $6(7.9 \%)$ did not have. These results also revealed that of the 70 health facilities with mobile telephone signals, 1 facility received up to 4 different signals, 21 facilities received 3 different signals, 32 facilities received 2 and 16 received only 1 signal. Of these 70 health facilities, $19(27.1 \%)$ indicated that telephone signals in their facilities were strong enough, 37(52.9\%) had strong signals, $10(14.3 \%)$ had low signals and $4(5.7 \%)$ with bad signals (Figure 5).

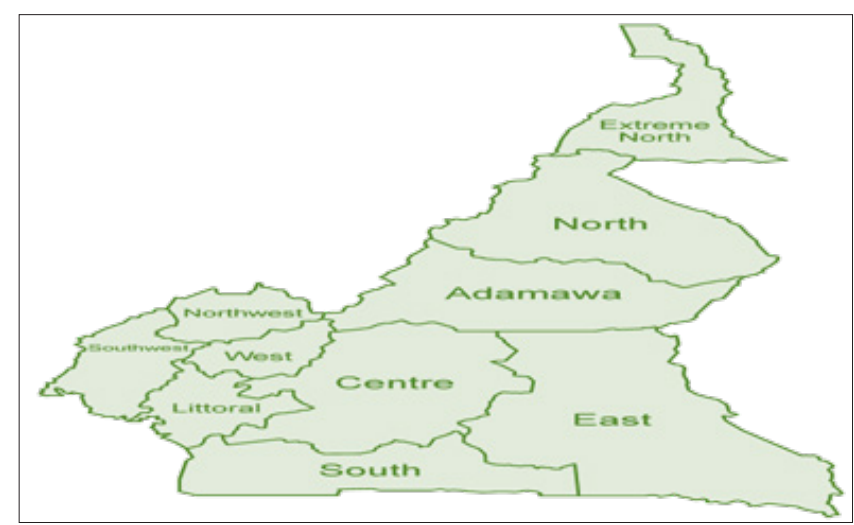

Figure 6: Map of the Republic of Cameroon.

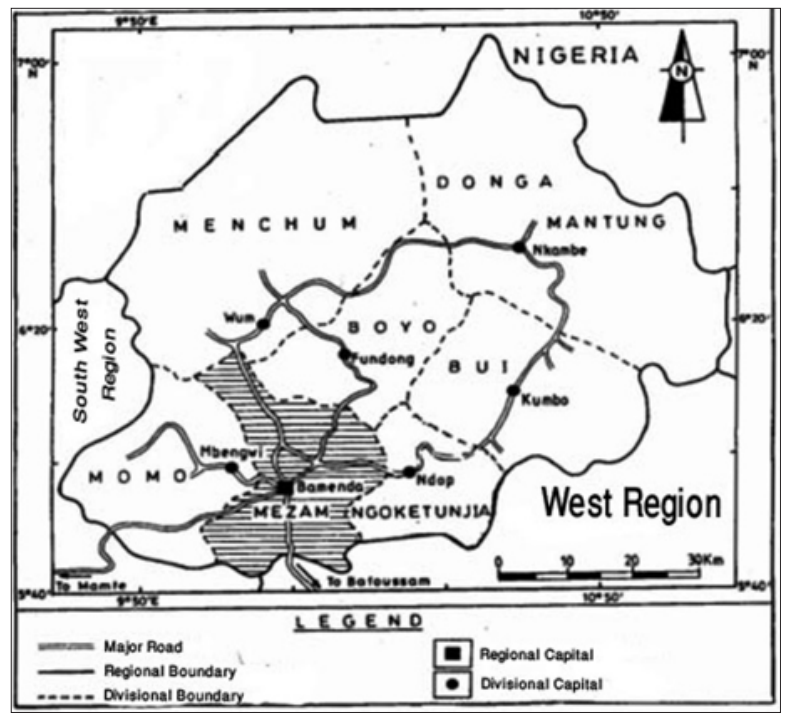

Figure 7: Map of the North West Region.

For internet services, 37(48.7\%) had internet while 39(51.3\%) did not have internet. Additional 33 facilities have the potentials of having internet since up to 70 of them receive mobile telephone signals and these mobile phone companies also have internet options. With this, one could conclude that ICTs in the NWR have reasonable coverage, a good potential for e-health development, this notwithstanding with some improvements (Figure 6). No studies could be found in this area to make comparisons. Other areas of test of heads of various health facilities knowledge on telemedicine, included the sending of an SMS or E-mail or a phone call to a colleague to get assistance to provide care to a patient, the breakdown of telemedicine in to store-and-forward and real time or interactive, the sending of an X-Ray via e-mail for a specialist to examine off site and the use of tele/video conference set ups or simple applications like Skype represented reasonable knowledge at $47(61.8 \%), 48(63.1 \%), 50(65.8 \%)$ and $59(77.6)$ respectively. $49(64.5 \%)$ of the respondents quantified the crises situation of the HRH in the Region to be acute, 21(27.6\%) said the crises was little, $1(1.3 \%)$ said there was no crises and $5(6.6 \%)$ did not know whether or not any crises exist (Figure 7).

The 5 who did not know whether a crisis existed or not were all from the rural health centers, a gross situation of lack of information. $49(64.5 \%)$ confirmed the viewpoint of this researcher ascertaining the fact that the NWR of Cameroon is experiencing acute shortage of HRH. To know if telemedicine could be introduced as part solution to these crises, $18(23.7 \%)$ of the respondents said they strongly agreed, 42(55.3\%) said they agreed, 7(9.2\%) said they disagreed and $9(11.8 \%)$ had no idea as to whether telemedicine could help in this crises situation or not. $60(80 \%)$ of the respondents at least agreed to the fact that telemedicine could be used as part solution to the crises, $64(84.2 \%)$ of the health facilities also said they had interest on their facilities linked to others via telemedicine (Figure 8). They equally advanced advantages of using telemedicine services such as reduction of the cost of referrals, seek specialized care, repaid interventions amongst others (Table 3). This is in line with a study carried out in India by Bowonder B et al. [4] who pointed out reducing the cost of service delivery, easy and quick access to the specialist and travel time reduction as some of the benefits of using telemedicine services.

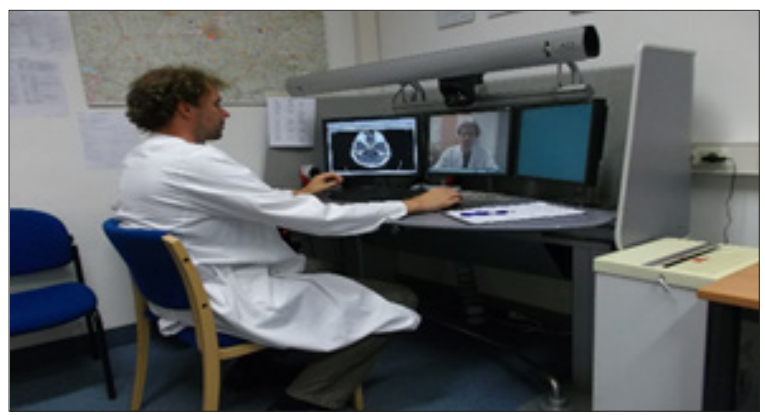

Figure 8: Visit of the TEMPiS Project at Harlaching Hospital, Munchen and Freising Klinik.

Photo Courtesy of Promise Aseh Munteh.

The disadvantages of using telemedicine to provide health care were also examined. As indicated (Table 4), lack of reliable internet services, regular power cuts and lack of finances to set up telemedicine infrastructures were pointed as the top disadvantages in this study (Figure $9 \& 10$ ). This is contrary to the results in a study carried out by Hjelm NM [5] who pointed to a breakdown in the relationship between health professionals and patients, a breakdown in relationship between health professionals, issue concerning the quality of health information and organizational and bureaucratic difficulties as the major drawbacks of telemedicine. 


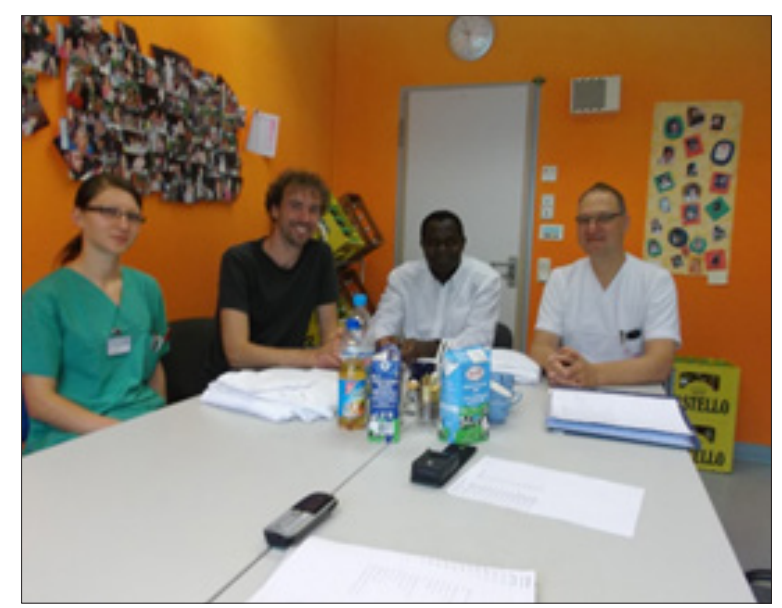

Figure 9: Photo courtesy of Freising Clinic Support Staff
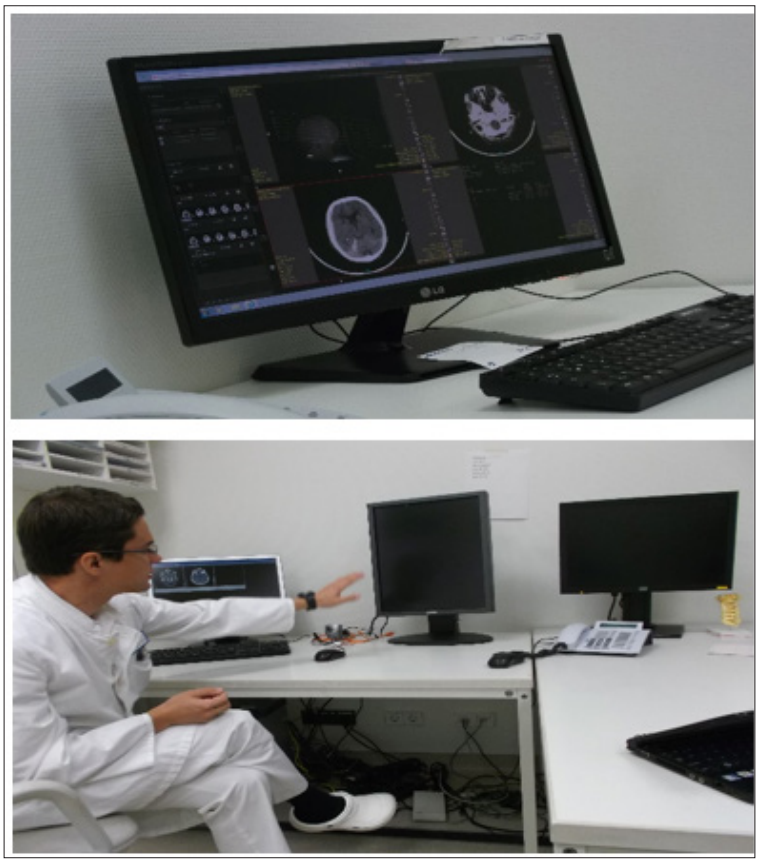

Figure 10: Visit to the Federal War Hospital Ulm, Germany.

Photos Courtesy of Promise Aseh Munteh.

\section{Recommendations}

To conclude, we saw that the:

A. NWR is facing an acute HRH crisis especially in the domains of specialized care with only 1 dermatologist, 2 orthopedics and so on (Table 7), only 92 midwives for a growing population like ours, 19 eye care staff, $23 \mathrm{X}$-Ray technicians and so on.

B. Most health facilities (especially the private ones) have reasonable infrastructures and specialties which will be of great importance to the entire Region if there is a general subscription to the use of ICTs to support the delivery of health care.

C. Telemedicine is not a new idea to many of our health administrators and thus could be expanded to save lives.
D. Issues of confidentiality which is one of the principal drawbacks to the rapid advancement of telemedicine in most developed countries was not highlighted as a challenge by the respondents in this study giving telemedicine a good place in the Region.

\section{Authors' Contributions}

PAM contributed in the design of the study, the collection and analysis of the data. WM and WS contributing in reading and correcting the manuscript to make it fit for publication.

\section{Acknowledgement}

This piece of work would not have been complete without the support of many people, some of whom I will like to mention here. 
A. Firstly, I remain grateful to God Almighty for seeing me through my studies.

B. Secondly, I am indebted to my supervisors, Prof. Wilfred Mbacham and Prof. Walter Swoboda for their guidance throughout this work.

C. Thirdly, I say a big thank you to Prof. Dr. Sibylle Brunner for all the encouragement and linkage to the University of Applied Sciences Neu-Ulm where I got great financial support and a second supervisor.

D. Fourthly, I wish to express my sincere gratitude to Dr. Nick Ngwanyam for offering me a job at the time I was most desperate. He may not know what he did to my family and I at the time he called me up for a job in his establishment.

E. Fifthly, I wish to sincerely thank the Catholic University of Cameroon (CATUC), Bamenda for offering me a chance to study at this level.

F. Sixthly, I extend a big thank you to Mr. Ndong Ignatius Cheng, Miss. Ngonga Linda Nchoune and Mrs. Viben Honorine, my colleagues in the office for all their encouragement and support.

G. Lastly and above all, I say thank you to my lovely wife Emilia, my daughters Kelly and Trixie and to my lovely boy Travis. They all went through hard times especially during the time I did not have a steady job to provide for their needs because of my decision to study.

\section{References}

1. Field MJ (1996) Telemedicine: A guide to assessing telecommunications in health care. Institute of Medicine (US) Committee on Evaluating Clinical Applications of Telemedicine, Washington, USA.

2. Lipson LR, Henderson TM (1996) State initiatives to promote telemedicine. Telemed J 2(2): 109-121.

3. Grigsby J, Sanders JH (1998) Telemedicine: Where it is and where it's going. Annals of Internal Medicine 129(2): 123-127.

4. Bowonder B, Mohit B, Sharnitha GA (2005) A Telemedicine platform: A case study of Apollo hospitals telemedicine project. International Journal of Services Technology and Management 6(3/4/5): 449-466.

5. Hjelm NM (2005) Benefits and drawbacks of telemedicine. J Telemedicine and Telecare 11(2): 60-70. 